\title{
Religiosity and Risky Sexual Behavior Among Adolescents in Sarawak, Malaysia
}

\author{
Albeny Joslyn Panting ${ }^{1} \&$ Teresa Yong Sui Mien ${ }^{2}$ \\ ${ }^{1}$ Open University Malaysia, Malaysia \\ ${ }^{2}$ Institute for Health Behavioral Research, National Institutes of Health, Malaysia \\ Correspondence: Albeny Joslyn Panting, Open University Malaysia, Kelana Jaya, Selangor, Malaysia. E-mail: \\ kongsi007@gmail.com
}

Received: September 16, 2020 Accepted: October 18, 2020 Online Published: October 30, 2020

doi:10.5539/gjhs.v12n13p49

URL: https://doi.org/10.5539/gjhs.v12n13p49

\begin{abstract}
Introduction: Risky sexual behavior is defined as a behavior that increases one's risk of contracting or being infected by sexually transmitted infections (STIs) and experiencing unintended pregnancies. This study examined the relationship between religiosity and risky sexual behavior among adolescents in the state of Sarawak, Malaysia.
\end{abstract}

Methods: The inclusion criteria included 1,146 unmarried adolescents aged between 16 and 19 years, whereby they answered a validated self-administered questionnaire using the modified Religion Scale and Risky Sexual Behavior - Unsafe Sex Scale. The analysis was restricted to respondents who reported to have had sex.

Results: Overall, the response rate recorded $95 \%(n=1,086)$, whereby the prevalence of respondents who reported that they have had sex was $9.5 \%, n=103$ (71 males, 32 females, mean age 17.82). Descriptive results further showed that the prevalence of those who have had sex for male and female were $6.53 \%$ and $2.94 \%$, respectively. The earliest sexual debut was revealed to be at 13 years of age. Moreover, bivariate analyses indicated a significant and negative correlation between religious practice and risky sexual behavior $(\mathrm{r}=-.23 ; \mathrm{p}<.05)$.

Conclusion: The study revealed that religious adolescents are more likely to avoid risky sexual behavior. This means that religious practice may become a potential protective factor in influencing adolescents to avoid risky sexual behaviors.

Keywords: religiosity, risky sexual behavior, adolescent, adolescence, unintended pregnancies

\section{Introduction}

According to the Communicable Disease Center, Atlanta (CDC, n.d.), risky sexual behavior is defined as behavior that increases one's risk of contracting or being infected by sexually transmitted infections (STIs) and experiencing unintended pregnancies. Such behaviors include having multiple partners, having casual sex with unknown partners, engaging in sex without condom usage, and using alcohol or drugs prior to or during sex (Turchik, 2009). Globally, literature regarding sexual behavior among adolescents indicates that this particular population may initiate sexual activity early during the adolescence years. Meanwhile, countries with higher rates of early marriage among young girls have recorded a greater proportion of this group engaging in sex, compared to their male counterparts (United Nations Population Fund [UNFPA], 2015).

According to literature, various negative outcomes are associated with premarital sex during adolescence, which include unwanted teenage pregnancy, illegal abortion, baby dumping, susceptibility to STIs and human immunodeficiency virus (HIV), teenage prostitution, and substance abuse (Panting, Abdullah, Roslan \& Ismail, 2019). It is estimated that on a global scale, around 16 million female adolescents deliver babies out of wedlock, while 3 million females aged between 15 and 19 years undergo unsafe abortion (World Health Organization [WHO], 2020).

In Malaysia, the prevalence of premarital sex among the adolescent population is increasing; data recorded in 1994 revealed a prevalence of 0.9 per cent (Malaysian Population and Family Development Board [MPFDB], 1994), which increased to 1.8 per cent in 1996 (Institute for Public Health [IPH], 1996) and 8.3 per cent in 2012 (IPH, 2012) before declining a little to 7.3 per cent in 2017 (IPH, 2017). In general, the understanding of sexual behavior 
and sexual health issues among the Malaysian adolescents requires an exploration into its multi-cultural context. Accordingly, this involves religion, belief systems, and the perception on sexuality issues, which may collectively play significant roles in shaping an adolescent's behavior (Low, 2009). In this respect, Moore and Rosenthal (2006) have underlined the need to look into the many variances globally in terms of sexual laws, mores, values, and practices when conducting a comparative study in sexual behavior. Among these elements, one particular facet is the manner in which religious practice and belief influence a person's engagement in risky sexual behavior. Religiosity heavily influences an adolescent's decision-making when dealing with different sexual issues, such as abstinence, birth control, and abortion (Lefkowitz, Gillen, Shearer, \& Boone, 2004).

It has been acknowledged in literature that religion may decrease people's overall involvement in risky behaviors through ordered instructions, such as practicing healthy behaviors, and specific prohibition, such as preventing people from indulging in risky behaviors (Mojahed, 2014). Furthermore, a systematic review regarding the relationships between religiosity and adolescent health attitudes and behaviors suggested that the varying measures of religiosity/spirituality may contribute to the positive effects on healthy attitudes and behaviors (Rew \& Wong, 2006). According to the Risk and Protective Model by Kirby and Lepore (2018), religion can be considered as a protective factor or risk factor. For example, adherence to one's religious beliefs may emerge as a protective factor, potentially discouraging one from engaging in premarital sex. In contrast, neglecting religious responsibilities may end up as a risk factor that encourages one to engage in risky sexual behavior.

Malaysia is a multi-religious country comprised of Islam, Christianity, Buddhism, Hinduism, and faiths of the minorities. In particular, Islam considers sex as one of the essential human needs that must be properly fulfilled, whereby illegal sex is prohibited regardless of the act's overall necessity. Moreover, anything that leads to illegal sex is also deemed as illicit in nature, such as free mixing of both sexes, provocative dressing, nudity, obscenity, and pornography (Athar, 2006). Sex in Islam is also considered as an act of devotion; those who engage in it with the right objective will be rewarded by God for such good deeds (Zain \& Yusoff, 2010).

Finn and Finn (2012) explained that Christianity views sexual relations, sanctioned through church marriage, as a sign of the worshippers' unconditional love for each other and a reflection of God's unquestioning love for the worshippers. As for Hinduism, the religion's moral traditions of sexual relations are embedded in its concept of idealized visions for the Hindu gods, which demonstrate the perfect balance of male and female relationship ("Hinduism", 2013).

Sarawak, the main location for this study, is a Malaysian state that comprises four major ethnic groups; mainly, the Iban, Chinese, Malay, and Orang Ulu. Being the majority of ethnic groups, most of the Ibans practice Christianity. Some still practice the traditional belief system, which is based on customary law, adat, in Iban language (Panting et al., 2019; Mawar, 2013). Adat refers to the unwritten traditional code governing all aspects of personal conduct from one's birth to death. It refers to the correct behavior towards the maintenance of moral order and values in the community. A violation of the adat is described as penyalah or a wrongful act in Iban language. For instance, premarital sex is considered as taboo or going against adat.

In this study, religiosity is measured by variables such as the importance of religion, belief in God, frequency of religious service attendance, frequency of prayer, and frequency of meditation. Globally, empirical evidence obtained among Muslim-dominated societies in Senegal has indicated that religiosity is associated with risky sexual behavior. According to a study by Gilbert (2008), an individual's religiosity can further reflect his/her cognitive, affective, and behavioral relationships with religion. The study undertaken in Senegal has focused on the manner in which Islam in the country indirectly acts as a control mechanism to maintain a low HIV or acquired immunodeficiency syndrome (AIDS) transmission rate. Among 234 undergraduate and graduate students who participated, those with higher religiosity scores have shown a higher tendency to abstain from sex. However, participants with higher religiosity scores are also not likely to report that they do not use condoms if they are sexually active.

Evidence derived from a 1997 National Longitudinal Survey of Youth in the United States, focused on the roles of family religiosity during early adolescence, has revealed that parents who attend religious services, parental prayers, and parental and familial religious activities are negatively associated with adolescent sexual activity, both directly and indirectly (Athar, 2006). The indirect association is mediated by family cohesion and negative peer behaviors, whereas the directly negative correlation is linked with contraceptive consistency among sexually active males.

On the contrary, a study has been conducted among 1,224 Muslim youths in Uganda to determine the association between religiosity and risky sexual behavior related to HIV transmission. It revealed that the behaviors associated with higher levels of religiosity elements, such as abstaining from sex, faithfulness in marriage, and avoiding 
substance use, may counter the negative behavioral elements likely to lead towards HIV transmission (Kagimu et al., 2013).

In the local context of Malaysia, rapid social changes as a result of urbanization and westernization have eroded the religious values among its adolescent population. This has resulted in adolescents perceiving themselves as less religious, being more open to western values, and starting to date early, which may be associated to premarital sex (Jaafar, Wibowo, \& Afiatin, 2006). In terms of the demographic profiles, Muslim adolescents from rural areas tend to have higher levels of religiosity than their urban counterparts (Krauss, Hamzah, \& Suandi, 2006). This finding is based on a cross-sectional study conducted among 1,692 youths from the four states of Kuala Lumpur, Johor, Kelantan, and Perlis, whereby each state is randomly represented by a mix of rural and urban sample populations. The authors have argued that these findings are due to the cultural differences between the ultra-modern (urban) and traditional (rural) groups, as a result of urbanization, modernization, and westernization.

Further empirical evidence has suggested that the more religious a person is, the less likely it is for him/her to be involved in social problems. This is based on a study exploring adolescents' views on selected elements of religion (i.e. ideological, ritualistic, intellectual, experiential, and consequential facets) and impacts on their involvement in social problems. The work involved a sample of 2,869 Muslim and non-Muslim students in Forms 1, 3, and 5 from several selected secondary schools in Johor, Malaysia (Noon, Haneef, Yusof, \& Amin, 2003). On a larger scale, a nationwide survey has been undertaken to identify the risks and protective factors associated with sexual activities among Malaysian adolescents aged 18 to 19 years. The findings revealed a prevalence of sexual activity at 6.4 per cent, whereby it is positively associated with low religiosity, anti-social behavior, female gender, risky behavior, history of abuse, and masturbation (Awaluddin et al., 2015).

The above-mentioned studies related to religiosity and risky sexual behavior in Malaysia have mostly been conducted among the advanced and more developed states of West Malaysia. Meanwhile, limited efforts have been undertaken in other less-developed but multi-ethnic states in East Malaysia (Borneo), such as the state of Sarawak (Panting et al., 2019). Therefore, Sarawak was chosen as the location for this study due to the unmet needs for generating an evidence-based policy geared towards sexual and reproductive health promotion strategies, especially among its adolescents comprised of various ethnic groups and religions. Thus, the main purpose of this study was to examine the relationship between religiosity and risky sexual behavior among adolescents in the state of Sarawak, Malaysia.

\section{Material and Methods}

This cross-sectional study investigated the association between religiosity (religious practice and religious belief) and risky sexual behavior among adolescents. The location selected for this study was the state of Sarawak. As one of the 13 states in Malaysia, it is located in the eastern part of the country, specifically in Borneo Island. Sarawak consists of 12 divisions or provinces. For this particular study, the selected provinces were Kuching, Sibu and Miri; whereby these three localities represented Sarawak in terms of the adolescent population (Department of Statistics Malaysia [DOSM], 2012).

\subsection{Sampling Procedures}

The sample size calculation for this study was conducted based on a formula by Naing, Winn and Rusli (2006), yielding an estimated sample size of 1,146. The sampling frame was derived from the list of districts, housing estates, and villages under the jurisdiction of their respective provincial offices. Then, the multi-stage sampling was utilized to select potential respondents from each chosen household. The inclusion criteria included adolescents aged 16 to 19 years old, their agreement to participate, consent obtained from the parents or guardians of those under 18 years of age regardless of whether they were still studying, and out-of-school adolescents who were unemployed or already working. Those who were married were excluded from this study.

\subsection{Data Collection Procedure}

The data collection utilized a self-administered questionnaire that was in Malay language (Bahasa Malaysia). Validation of the study instrument was conducted in a pilot study undertaken in the province of Samarahan, Sarawak, Malaysia.

\subsection{Instrument}

Socio-demographic variables include, for example, gender, age, ethnicity, religious affiliation, level of education, and occupational status. Religiosity was measured using a validated Religion Scale (RS) in Malay language, which was adapted from the MPFDB (2012) and had a Cronbach's alpha of 0.9 from a previous study. The internal consistency for the current study was 0.86 , which was considered as high and acceptable. The RS comprised of two 
sub-scales, namely Religious Practices (RP) (i.e. four items) and Religious Belief (RB) (i.e. five items). Example of items for RP are: (a) My religious practices and praying could educate my soul to seek a peaceful life, and (b) I have committed a sin if my behavior contradicted with my religion. Meanwhile, items for RB include: (a) My religion is my main strength to prevent me from engaging in premarital sex, and (b) My strong religious belief could prevent me from committing sins. For each item, the response ranged from $1=$ strongly disagree to $4=$ strongly agree. The score range for subscales Religion-RP and Religion-RB was between $4-16$ and $5-20$, respectively. Meanwhile, the overall score range for RS was between 9 and 36, whereby higher scores indicated higher levels of religious commitment. For the purpose of this study, the cut-off point for the mean scores is as follows: $<$ mean scores $=$ less religious, and $\geq$ mean scores $=$ highly religious.

Risky sexual behavior was measured using the Risky Sexual Behavior - Unsafe Sex Scale (RSB-USS), which consisted of five items in Malay language and adapted from the works of Rahim and Herman (1996) and MPFDB (2012). The response was in the categorical scale of YES or NO. Scoring for each item included giving point 1 or 0 , depending on the response weightage. For example: how many sex partners for the past 12 months (score 1 if more than one and 0 for single partner); use condom (score 0 if YES and 1 if $\mathrm{NO}$ ); had sex under alcohol influence (score 1 if YES and 0 if NO); had sex under drug influence (score 1 if YES and 0 if NO); and forced by partner to have sex (score 1 if YES and 0 if NO). The RSB-USS sum score range is between 0 and 5 in which a higher score indicates a higher risk of involvement in unsafe sex. For the purpose of this study, a cut-off point for the scores are as indicated: $0=$ safe sex, and $\geq 1=$ higher risk of risky sexual behavior.

\subsection{Analysis}

Data were analyzed using SPSS for WINDOWS version 22, which involved descriptive analysis and bivariate non-parametric analyses. Firstly, descriptive statistics was utilized to examine the prevalence of those who have had sex according to the socio-demographic characteristics, while bivariate non-parametric analyses were used to determine the association between religion and risky sexual behavior. Furthermore, the normality test was conducted to indicate whether the RS and RSB-USS were skewed. Non-parametric correlational analyses were thus employed to determine the relationship between RS, RP, RB, and RSB-USS. Accordingly, a probability value $p<.05$ was considered to be statistically significant at $95 \% \mathrm{CI}$ in the analysis.

\subsection{Ethical Considerations}

Ethical approval was obtained from the Medical Research Ethics Committee (MREC), Ministry of Health, Malaysia. For respondents below 18 years of age, informed consent was sought from their parents or guardians. Vital information regarding the objective and benefits of the study were explained to the respondents and their parents or guardians accordingly.

\section{Results}

\subsection{Overview of Respondents}

Out of the total sample size of 1,146 for this study, the response rate was $95 \%(\mathrm{~N}=1,086)$. Overall, the prevalence rate of respondents who reported to have had sex was $9.5 \%(n=103)$. This analysis focused on the data for respondents who reported to have had sex. The details are shown in Table 1.

Table 1. Prevalence of respondents who have had sex according to socio-demographic characteristics

\begin{tabular}{lc}
\hline Characteristic & Prevalence (\%) \\
\hline Gender & \\
Male & 6.53 \\
Female & 2.94 \\
\hline Location & \\
Urban & 7.27 \\
Rural & 2.20 \\
\hline Age group & \\
$13-15$ & 0.18 \\
$16-18$ & 5.80 \\
$19-21$ & 3.49 \\
\hline
\end{tabular}




\section{Ethnic group}

Iban

Malay

Chinese

1.84

Bidayuh

0.92

Orang Ulu

0.46

\begin{tabular}{ll}
\hline Religion & \\
Christianity & 4.14 \\
Islam & 2.85 \\
Buddhism & 1.10 \\
Traditional Chinese religion & 0.64 \\
Traditional native religion & 0.55 \\
\hline Status & \\
Studying & 6.07 \\
Working & 2.48 \\
Unemployed & 0.92 \\
\hline
\end{tabular}

\subsection{Sexual Debut}

Among the respondents who reported to have had sex $(n=103)$, the results of the earliest age reported (i.e. sexual debut) are shown in Table 2. The earliest sexual debut was at 13 years old $(0.97 \%)$, whereas a higher percentage of the respondents reported their sexual debut at 16 years of age $(34.9 \%)$.

Table 2. Sexual debut by age

\begin{tabular}{lc}
\hline Earliest age reported to have had sex & Percentage \\
\hline 13 years old & 0.97 \\
15 years old & 23.3 \\
16 years old & 34.9 \\
17 years old & 22.3 \\
\hline
\end{tabular}

\subsection{Religiosity and Risky Sexual Behavior}

Table 3 shows the overall mean score among the respondents reported to have had sex $(n=103)$. The value for religiosity was $29.87(\mathrm{SD}=4.94$, range $11-36)$, whereas the average score for risky sexual behavior was 1.11 (SD $=1.00$, range $0-5)$.

Table 3. Mean score for religiosity and risky sexual behavior

\begin{tabular}{lllll}
\hline Domain & Mean Score & SD & Median & Range \\
\hline Religiosity & 29.87 & 4.94 & 31 & $11-36$ \\
Risky Sexual Behavior & 1.11 & 1 & 1 & $0-5$ \\
\hline
\end{tabular}

Table 4 shows the results regarding the mean score according to other demographic characteristics among the respondents who have had sex $(n=103)$. The mean score for religiosity among the female respondents (mean $=30.3$, $\mathrm{SD}=4.46$ ) was higher than their male counterparts. The result further revealed that the respondents who were not affiliated with any religion (i.e. no religion) scored the lowest for religiosity (mean=21.50, $\mathrm{SD}=5.39$ ), while scoring highest for risky sexual behavior (mean=1.50, $\mathrm{SD}=2.12$ ). 
Table 4. Mean score for religiosity and risky sexual behavior according to socio-demographic characteristics

\begin{tabular}{|c|c|c|c|c|}
\hline \multirow{2}{*}{ Characteristics } & \multicolumn{2}{|c|}{ Religion Scale (RS) } & \multicolumn{2}{|c|}{ Risky Sexual Behavior-Unsafe Sex Scale (RSB-USS) } \\
\hline & Mean & SD & Mean & SD \\
\hline \multicolumn{5}{|l|}{ Gender } \\
\hline Male & 29.80 & 5.17 & 1.13 & 0.92 \\
\hline Female & 30.3 & 4.46 & 1.06 & 1.19 \\
\hline \multicolumn{5}{|l|}{ Location } \\
\hline Urban & 30.01 & 4.58 & 1.13 & 1.03 \\
\hline Rural & 29.41 & 6.07 & 1.04 & 0.90 \\
\hline \multicolumn{5}{|l|}{ Ethnic group } \\
\hline Iban & 29.50 & 5.82 & 1.03 & 1.01 \\
\hline Chinese & 28.25 & 5.29 & 1.00 & 0.92 \\
\hline Malay & 30.93 & 3.71 & 1.19 & 1.14 \\
\hline Bidayuh & 30.30 & 4.92 & 1.50 & 0.85 \\
\hline Orang Ulu & 32.20 & 1.78 & 1.00 & 0.71 \\
\hline \multicolumn{5}{|l|}{ Religion } \\
\hline Islam & 30.93 & 3.71 & 1.19 & 1.13 \\
\hline Christianity & 30.13 & 5.28 & 1.09 & 0.96 \\
\hline Buddhism & 28.08 & 5.58 & 1.25 & 0.96 \\
\hline Traditional Chinese religion & 29.42 & 4.82 & 0.71 & 0.75 \\
\hline Traditional native religion & 29.33 & 4.82 & 0.83 & 0.75 \\
\hline No religion & 21.50 & 5.39 & 1.50 & 2.12 \\
\hline
\end{tabular}

Religiosity: $<29.87=$ less religious, and $\geq 29.87=$ highly religious .

Risky Sexual Behavior: $0=$ safe sex, and $\geq 1=$ higher risk.

\subsection{Bivariate Analysis}

Table 5 shows a significantly negative correlation between one of the sub-domains of religiosity (i.e. religious practice) and risky sexual behavior $(\mathrm{r}=-.23 ; \mathrm{p}<.05)$.

Table 5. Correlations between religiosity (religious practice and religious belief) and risky sexual behavior

\begin{tabular}{lllll}
\hline & 1 & 2 & 3 & 4 \\
\hline 1. Religious Practice & 1 & & & \\
2. Religious Belief & .55 & 1 & & \\
3. Religiosity & .82 & .91 & -.08 & -.17 \\
4. Risky Sexual Behavior & $-.23^{*}$ & & 1 \\
\hline
\end{tabular}

$* \mathrm{p}<.05$.

\section{Discussion}

The main purpose of this study was to determine the relationship between religion and risky sexual behavior among adolescents in the state of Sarawak, Malaysia. Descriptive analyses showed that the prevalence of premarital sex was $9.5 \%$ and the earliest sexual debut was at 13 years of age. There may be other possible reasons behind adolescents engaging in premarital sex, which are attributed to complex and various social contexts. They include the lack of knowledge and appropriate skills on sexual and reproductive health, influence by peers, familial 
conflicts, lack of religious education, and the negative influence of internet and communication technology (ICT) (UNFPA, 2015).

Interestingly, urban respondents scored higher on the religious score than their rural counterparts, whereas their RSB-USS scores were much lower. This finding contradicts the study by Krauss, Hamzah and Suandi (2006), which pointed out that Muslim youths from rural areas tend to have higher levels of religiosity than their urban counterparts. However, the outcome is supported by Jaafar, Wibowo and Afiatin (2006), who indicated that social changes, such as urbanization and westernization, may influence adolescents to engage in risky sexual behavior, such as premarital sex.

Other findings according to ethnic groups showed that Orang Ulu, one of the minority ethnic groups in the state of Sarawak, had the highest average religious score. Interestingly, it was noted that their average RSB-USS score was also among the lowest. Previous literature has supported these findings, whereby a study by Noon et al. (2003) pointed out that the more religious a person is, the less likely it is for him/her to be involved in social problems. This finding also supports Kagimu et al. (2013), who found that behaviors associated with higher levels of religiosity elements, such as abstaining from sex, faithfulness in marriage, and avoiding substance use, may counter the negative behavioral elements likely to lead towards HIV transmission.

Other key findings from this study showed that religious practices were negatively correlated with risky sexual behavior. This indicates that the more religious an adolescent is, the more likely for the adolescent to avoid risky sexual behavior. It shows that religious practices may have some potential influence in adolescents' involvement in risky behaviors, thereby possibly becoming either a protective or risk factor (i.e. lack of). In the context of Malaysia, a study on religiosity and social problems has shown that the more religious an individual is, the less likely it is for him/her to be involved in social problems (Noon et al., 2003). While in the United States, the strength of religious practices among the American society contributes to the formation of personal moral code and moral judgments (Hawes \& Berkley-Patton, 2014). These findings are also in line with another study that investigated the association between religiosity and sexual behaviors among an African American church-based population, which has reported God-consciousness to be protective factors against risky sexual behavior (Sinha, Cnaan, \& Gelles, 2007).

In general, the aim of sexual and reproductive health education programs among the adolescent population is to inculcate their knowledge and awareness regarding the importance of adopting preventive health behaviors. This includes adopting healthy lifestyles in which the strategies can strengthen their resilience against risky behavior (UNFPA, 2015). Therefore, the findings in this study, especially the role of religious practice, can be considered as a protective factor according to Kirby and Lepore's Risk and Protective Model (2018). For example, adherence to one's religious beliefs may become a protective factor, which potentially discourages one from engaging in premarital sex. In contrast, neglecting one's religious responsibilities can become a risk factor that may encourage involvement in risky sexual behavior. In addition, adolescence is a crucial phase; it is a period of opportunity for an individual to nurture and develop the capabilities required for achieving one's full potential and a healthy life (UNFPA, 2015).

As this study explored the sexual behavior of respondents in the context of their relationship with religion, it was possible that the respondents did not answer the questionnaires honestly. This might be due to biased factors such as social desirability, even though relevant measures were taken, such as assuring their confidentiality and privacy. Moreover, this study focused on the state of Sarawak and might not represent adolescent populations in other parts of Malaysia, which are comprised of different cultures and belief systems. Thus, it is recommended for future studies to utilize a better method that would address this problem.

\section{Conclusion}

In conclusion, religious practices were negatively correlated with risky sexual behavior. The study revealed that religious adolescents are more likely to avoid risky sexual behavior. This means that religious practice may become a potential protective factor in influencing adolescents to avoid risky sexual behaviors.

\section{Funding}

There is no funding.

\section{Acknowledgements}

The authors would like to thank the Medical Research and Ethics Committee, Ministry of Health, Malaysia for ethical approval. Our deepest gratitude goes to all the respondents who participated and those who assisted both directly and indirectly in this study. 


\section{Competing Interests Statement}

The authors declare that there are no competing or potential conflicts of interest.

\section{References}

Athar, S. (2006). Sex Education: An Islamic Perspective. Selangor Darul Ehsan. Malaysia: Masterpiece Publication Sdn. Bhd.

Awaluddin, S. M., Ahmad, N. A., Saleh, N. H., Aris, T., Kasim, N. M., Sapri, N. A. M., \& Rashid, N. R. K. (2015). Prevalence of sexual activity in older Malaysian adolescents and associated factors. Journal of Public Health Aspects, 2(1). https://doi.org/10.7243/2055-7205-2-1

Centers for Disease Control and Prevention, Atlanta (CDC). (n.d.). Alcohol and drug use. Retrieved from https://www.cdc.gov/alcohol

Department of Statistics Malaysia (DOSM). (2012). Social statistics bulletin Malaysia. Putrajaya: Malaysia: Department of Statistics Malaysia.

Finn, T., \& Finn, D. (2012). Love, Sex and the Catholic Church. Boston, MA: Pauline Books \& Media.

Gilbert, S. G. (2008). The influence of Islam on AIDS prevention among Senegalese university students. AIDS Education and Prevention, 2008(20), 399-407. https://doi.org/10.1521/aeap.2008.20.5.399

Hawes, S. M., \& Berkley-Patton, J. Y. (2014). Religiosity and risky sexual behaviors among an African American church-based population. J Relig Health, 53(2), 469-482. https://doi.org/10.1007/s10943-012-9651-4

Hinduism. (2013). Retrieved June 15, 2020, from http://www.hinduism.co.za

Institute for Public Health. (1996). The national health and morbidity survey 1996. Kuala Lumpur, Malaysia: Ministry of Health Malaysia.

Institute for Public Health. (2012). The national health and morbidity survey: Malaysia global school-based student health survey 2012. Kuala Lumpur, Malaysia: Ministry of Health Malaysia.

Institute for Public Health. (2017). The national health and morbidity survey: Adolescents Health Survey 2017. Kuala Lumpur, Malaysia: Ministry of Health Malaysia.

Jaafar, J., Wibowo, I., \& Afiatin, T. (2006). The relationship between religiosity, youth culture, and premarital sex among Malaysian and Indonesian adolescents. Asia Pacific Journal of Social Work and Development, 16. https://doi.org/10.1080/21650993.2006.9755999

Kagimu, M., Guwatudde, D., Rwabukwali, C., Kaye, S., Walakira, Y., \& Ainomugisha, D. (2013). Religiosity for promotion of behaviors likely to reduce new HIV infections in Uganda: A study among Muslim youth in Wakiso district. Journal Religion and Health, 52, 1211-1227. https://doi.org/10.1007/s10943-011-9563-8

Kirby, D., \& Lepore, G. (2018). The national campaign to prevent teen \& unplanned pregnancy: sexual risk \& protective factors. Retrieved from http://traversecityfamilylaw.com.

Krauss, S. E., Hamzah, A. H., \& Suandi, T. (2006). Exploring regional differences in religiosity among Muslim youth in Malaysia. Rev of Religious Research, 47(3), 238-252. Retrieved from https://www.jstor.org/stable/3512356

Lefkowitz, E. S., Gillen, M. M., Shearer, C. L., \& Boone, T. L. (2004). Religiosity, sexual behaviour, and sexual attitudes during emerging adulthood. The Journal of Sex Research, 4, 150-159. https://doi.org/10.1080/00224490409552223

Low, W. Y. (2009). Malaysian youth: issues and challenges. JUMMEC, 12(1), 3-14. https://doi.org/10.22452/jummec.vol12no1.2

Malaysian Population and Family Development Board (MPFDB). (1994). Malaysian Population and Family Surveys III. Kuala Lumpur, Malaysia: Malaysian Population and Family Development Board.

Malaysian Population, Family and Development Board (MPFDB). (2012). Kajian faktor risiko dan pelindung terhadap kesihatan reproduktif dan seksual remaja di Semenanjung Malaysia. Kuala Lumpur, Malaysia: Malaysian Population, Family and Development Board.

Mawar, G. (2013). Iban Cultural Heritage. Retrieved from Mawar Blogspot website: http://gnmawar.wordpress.com/adat_iban/

Mojahed, A. (2014). Religiosity and preventing risky behaviors. Int J High Risk Behav Addict, 3(3), e2284. 
https://doi.org/10.5812/ijhrba.22844

Moore, S., \& Rosenthal, D. (2006). Sexuality in adolescence: current trends. New York: Routledge. https://doi.org/10.4324/9780203695036

Naing, L., Winn, T., \& Rusli, B. N. (2006). Sample size calculator for prevalence studies. Retrieved from the website: http://www.kck.usm.my/ppsg/stats_resources.htm

Noon, H. M., Haneef, M., Yusof, S., \& Amin, R. M. (2003). Religiosity and Social Problems in Malaysia. $\begin{array}{llll}\text { Intellectual } & \text { Discourse, } & \text { Retrieved } & \text { from }\end{array}$ https://journals.iium.edu.my/intdiscourse/index.php/id/article/view/247

Panting A. J., Abdullah, H., Roslan, S., \& Ismail I. A. (2019). Potential social risk factors for teenage pregnancy in Sarawak. Pertanika Journal of Social Sciences \& Humanities, 27(1), 425-441. Retrieved from http://psasir.upm.edu.my/id/eprint/67816

Rahim, S. A., \& Herman, I. (1996). Remaja dan AIDS. Media, Nilai, Personaliti, dan Tingkah Laku. Kuala Lumpur, Malaysia: Ministry of Health Malaysia \& Universiti Kebangsaan Malaysia.

Rew, L., \& Wong Y. J. (2006). A systematic review of associations among religiosity/spirituality and adolescent health attitudes and behaviors. $J$ Adolescent Health, 38(4), $433-42$. https://doi.org/10.1016/j.jadohealth.2005.02.004

Sinha, J. W., Cnaan, R. A., \& Gelles, R. J. (2007). Adolescent risk behaviors and religion: findings from a national study. J Adolesc, 30(2), 231-49. https://doi.org/10.1016/j.adolescence.2006.02.005

Turchik, J. A., \& Garske, J. P. (2009). Measurement of sexual risk taking among college students. Archives of Sexual Behavior, 38(6), 936-48. https://doi.org/10.1007/s10508-008-9388-z

United Nations Population Fund (UNFPA). Sexual and reproductive health of young people in Asia and the Pacific. A review of issues, policies, and programmes. Bangkok, Thailand: UNFPA. Retrieved from https:/asiapacific.unfpa.org/en/publications/sexual-and-reproductive-health-young-people-asia-and-pacific

World Health Organization (WHO). (2020). Adolescents sexual health. Retrieved from https://www.who.int/en/news-room/fact-sheets/detail/adolescent-pregnancy

Zain, A. A., \& Yusoff, M. Y. (2010). Pendidikan seks dari perspektif Islam. Kuala Lumpur, Malaysia: Utusan Publications \& Distributors Sdn. Bhd.

\section{Copyrights}

Copyright for this article is retained by the author(s), with first publication rights granted to the journal.

This is an open-access article distributed under the terms and conditions of the Creative Commons Attribution license (http://creativecommons.org/licenses/by/4.0/). 